\title{
Wild Arctic char Salvelinus alpinus and trout Salmo trutta: hosts and reservoir of the salmonid pathogen Spironucleus salmonicida (Diplomonadida; Hexamitidae)
}

\author{
Anders Jørgensen ${ }^{1, *}$, Kari Torp ${ }^{2}$, Marie A. Bjørland ${ }^{2}$, Trygve T. Poppe ${ }^{2}$ \\ ${ }^{1}$ Norwegian Veterinary Institute, PO Box 750 Sentrum, 0106 Oslo, Norway \\ ${ }^{2}$ Norwegian School of Veterinary Science, PO Box 8146 Dep, 0033 Oslo, Norway
}

\begin{abstract}
Spironucleus salmonicida is a diplomonad flagellate known to cause systemic infections in farmed salmonids. In northern Norway, outbreaks of spironucleosis in farmed Atlantic salmon Salmo salar have been a recurring problem. Common to all these outbreaks was the origin of smolts: all came from the same farm. In the present study, wild Arctic char Salvelinus alpinus and brown trout Salmo trutta were sampled from the lakes used as a water source for the smolt supplier. In addition, smolt and three-spined sticklebacks Gasterosteus aculeatus were sampled from the smolt farm. Bile and intestinal contents from the sampled fish were examined by light microscopy and PCR. Spironucleus salmonicida was identified in both wild Arctic char and brown trout from the lakes used as water sources by the smolt farm, suggesting that the farmed fish were exposed to this pathogen before transfer to the sea. Spironucleus barkhanus and Spironucleus salmonis were also identified in the sampled fish. The present study also demonstrated that infections with multiple Spironucleus species are present in wild salmonids. No indications of disease related to diplomonad infections were observed in the wild fish, suggesting that wild salmonids are reservoir hosts of Spironucleus salmonicida.
\end{abstract}

KEY WORDS: Co-infection - Farmed Atlantic salmon · Fish disease · Hatchery Protozoa · Spironucleosis $\cdot$ SSU rDNA

\section{INTRODUCTION}

Diplomonad flagellates of the genus Spironucleus may cause severe systemic infections in both ornamental and farmed fish. Systemic spironucleosis in farmed salmonids may cause mass mortalities and huge economic losses as the fish are unsuitable for human consumption (Mo et al. 1990, Paull \& Matthews 2001). The first case of systemic spironucleosis (reported as hexamitosis) in farmed Atlantic salmon Salmo salar was reported from a marine fish farm in northern Norway in November 1989 (Mo et al. 1990). In the following years, additional outbreaks were observed (Poppe et al. 1992, Poppe \& Mo 1993), and hexamitid flagellates indistinguishable from Hexamita salmonis (current valid name Spironucleus salmonis) were identified by light micoscopy in smears and imprints from visible lesions from a wide range of different organs (Poppe \& Mo 1993). In 1991, an outbreak of systemic spironucleosis (hexamitosis) was observed in farmed chinook salmon Oncorhynchus tshawytscha in Canada (Kent et al. 1992). The infectious agent was identified by light microscopy as H. salmonis.

Electron microscopy was initially considered essential for identification of species belonging to the genus Spironucleus (Poynton \& Sterud 2002). Sterud et al. (1997) presented a scanning and transmission 
electron microscopy (SEM and TEM) study of hexamitid flagellates from farmed Atlantic salmon with systemic infection where ultrastructural data showed that the hexamitid flagellate causing systemic disease in farmed Atlantic salmon was different from $H$. salmonis. The ultrastructural features of the studied hexamitid flagellate were consistent with those of the genus Spironucleus. However, this flagellate could be clearly distinguished from other species within this genus; thus the species Spironucleus barkhanus was established. The same study also showed that $S$. barkhanus was present in the intestine and gall bladder of grayling Thymallus thymallus. Grayling was chosen as the type host of $S$. barkhanus as the infection was endemic and highly prevalent in these fish (close to $100 \%$ ), compared to the more sporadic outbreaks in farmed Atlantic salmon. Spironucleus barkhanus was later described as an apparent commensal in the gall bladder of wild Arctic char Salvelinus alpinus (Sterud et al. 1998), and some years later $S$. barkhanus was also identified as the cause of spironucleosis in farmed Arctic char (Sterud et al. 2003). Populations of Arctic char in lakes connected to the sea by rivers or streams may contain both resident and anadromous fish. Migratory fish make short migrations to the sea during the summer months for feeding and were considered to be the source of the infectious agent causing systemic spironucleosis in farmed salmonids (Sterud et al. 1998). A study of an outbreak of systemic spironucleosis in farmed Arctic char showed that the parasite from the gall bladder of wild Arctic char was genetically very different from the isolates causing systemic disease in the farmed fish (Jørgensen \& Sterud 2004). The differences in the small subunit ribosomal RNA (SSU rRNA) gene were of such magnitude that the conspecificity of these isolates was questioned (Jørgensen \& Sterud 2004). A more comprehensive study included several new parasite isolates obtained from both wild and farmed salmonids with a wide geographic distribution (Jørgensen \& Sterud 2006). In addition, nucleotide sequence data from the SSU rRNA, $\alpha$-tubulin and glutamate dehydrogenase genes were analysed and lead to the redescription of the pathogenic isolate infecting farmed salmonids as S. salmonicida. The cause of systemic spironucleosis in marine farmed salmonids was thus finally identified as S. salmonicida. However, the wild and 'primary' host of $S$. salmonicida was never identified (Jørgensen \& Sterud 2006).

Since the first outbreak of the disease in 1990, sporadic cases of the disease have been registered at the Norwegian Veterinary Institute. All Atlantic salmon farms in Norway that have experienced systemic spironucleosis have received smolts from the same smolt farm. Fish from this farm, and fish from the water source of this farm, have previously been examined for the presence of diplomonad flagellates, but were never found to be positive (T. T. Poppe pers. obs.). To further explore the possibility of a reservoir of $S$. salmonicida in the 3 lakes used as water sources for this smolt farm, wild fish were sampled and analysed for the presence of diplomonad flagellates.

\section{MATERIALS AND METHODS}

\section{Sampling}

Wild brown trout Salmo trutta and wild Arctic char were caught by angling and gill nets in the Store Måsvatn, Helvetjavrri and Landersfjordvatnet lakes, indicated as localities A, B and C in Fig. 1, respectively. These lakes are used as water sources for the smolt farm (referred to as Company A) suspected to have delivered smolts infected with Spironucleus salmonicida. Sampling was carried out from 7 to 31 July and from 15 to 19 September 2008. Fish were killed by a blow to the head and examined in the laboratory at the smolt farm. In total, 20 trout and 48 Arctic char were sampled in the 3 lakes (see Table 1 for more detailed information). Furthermore, 240 Atlantic salmon smolts were sampled from freshwater tanks and 1 saltwater tank at the farm. In addition, 12 three-spined sticklebacks Gasterosteus aculeatus were sampled from several freshwater tanks at the farm. All fish were kept at $4^{\circ} \mathrm{C}$ in a fridge (up to $8 \mathrm{~h}$ ) until full necropsy. In addition to bile, digesta and mucus of the intestine, organs that showed signs of pathology were examined by light microscopy (100 to $400 \times$ ) for the presence of diplomonad flagellates. Positive samples were preserved in $96 \%$ ethanol for molecular analyses. See Table 1 for a complete list of samples, hosts and sample localities. A subset of the fish sampled at the smolt farm and wild fish caught in September were only subjected to molecular analysis (see Table 1).

\section{DNA extraction}

Aliquots of $1 \mathrm{ml}$ ethanol-preserved bile or intestinal content were centrifuged for a minimum of $5 \mathrm{~min}$ at $3000 \times g$. The pellets were resuspended in phosphate-buffered saline (PBS), centrifuged for $5 \mathrm{~min}$ at $3000 \times g$ and resuspended in $200 \mu \mathrm{l}$ PBS. The 


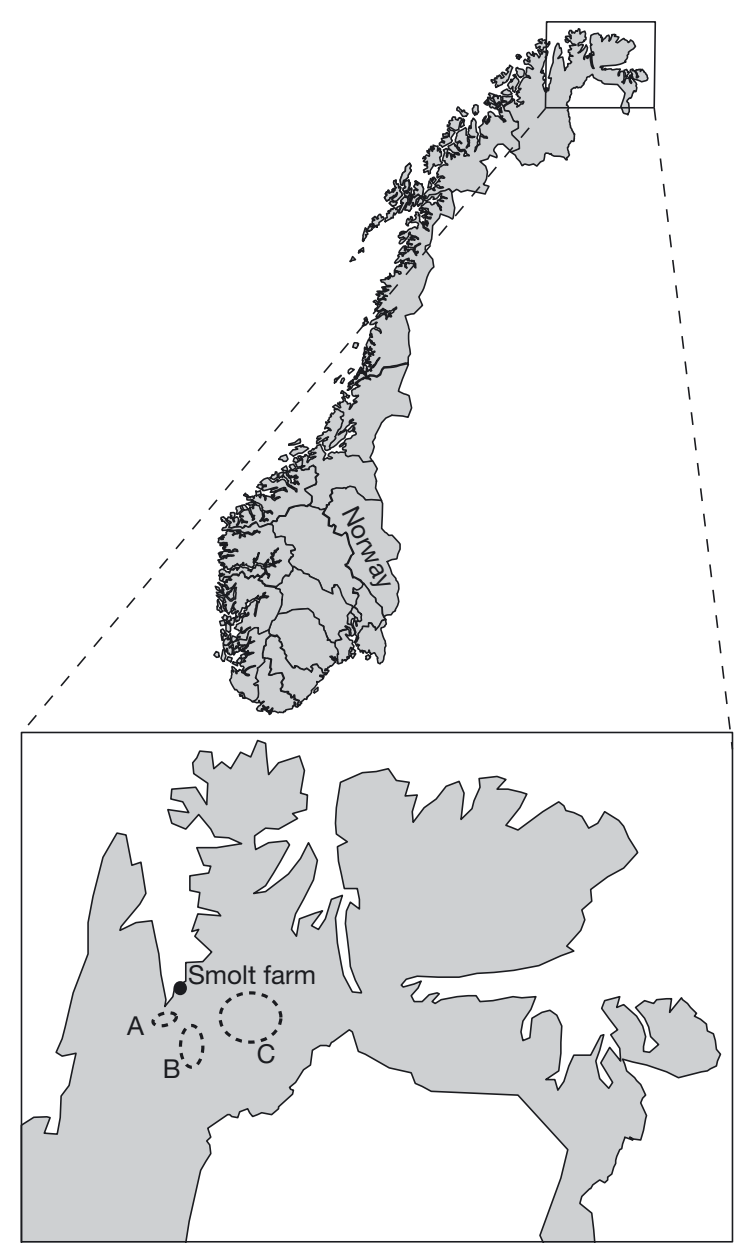

Fig. 1. Location of the smolt farm, and the Landersfjordvatnet (A), Helvetjavrri (B) and Store Måsvatn (C) lakes in northern Norway

QIAamp DNA Stool Mini Kit (Qiagen) was used for 'intestinal' samples, while the NucleoSpin Tissue kit (Macherey Nagel) was used to extract DNA from lesions/abscesses and bile samples. For intestinal samples, DNA was eluted in $100 \mu \mathrm{l}$ of the supplied Buffer AE (Qiagen). Samples extracted using the Nucleospin kit (Macherey Nagel) were eluted in $200 \mu \mathrm{l}$ of the supplied Buffer EB.

\section{PCR, cloning and sequencing of the SSU rDNA}

All samples positive for hexamitid flagellates by light microscopy were analysed by PCR using 2 nested PCR protocols. The general eukaryotic primers ERIB 1 (5'-ACC TGG TTG ATC CTG CCA G-3') (Fiala 2006) and EUKB (5'-ATC CTT CTG CAG GTT CAC CTA C-3') (Medlin et al. 1988) were used in the first reaction. The primer set Spiro-1f (5'-AAG ATT
AAG CCA TGC ATG CC-3') and Spiro-2r (5'-GCA GCC TTG TTA CGA CTT CTC-3') was used in nested reactions for amplification of Spironucleus spp. The primer set Spironucleosis-1f (5'-TCA TTT ATC AGT GGT TAG TAC ATG C-3') and Spironucleosis-2r (5'-TTC AAG CCT AAC CAC GAC AAG$\left.3^{\prime}\right)$ was used in nested reactions for amplification of $S$. salmonicida (Jørgensen \& Sterud 2004). The nested PCR protocols were used for increased sensitivity.

The $50 \mu \mathrm{l}$ reaction mix contained $5 \mu$ l of template DNA, $500 \mu \mathrm{M}$ of each primer, $200 \mu \mathrm{M}$ of each dNTP, $50 \mathrm{mM} \mathrm{KCl}, 1.5 \mathrm{mM} \mathrm{MgCl}_{2}, 10 \mathrm{mM}$ Tris-HCl (pH 9 at room temperature) and 2.5 units of Taq DNA polymerase (GE Health). The following thermal parameters were used to amplify the SSU rDNA fragments: initial denaturation at $95^{\circ} \mathrm{C}$ for $5 \mathrm{~min}$, then 35 cycles of denaturation at $95^{\circ} \mathrm{C}$ for $45 \mathrm{~s}$, annealing at $50^{\circ} \mathrm{C}$ for $45 \mathrm{~s}$ and extension at $72^{\circ} \mathrm{C}$ for $45 \mathrm{~s}$. After 35 cycles an extension step at $72^{\circ} \mathrm{C}$ for 4 min was included to ensure complete elongation of all products. The nested reaction contained $5 \mu \mathrm{l}$ of the first reaction as template DNA and used the thermal cycling conditions as described above, except that the annealing temperature was set to $56^{\circ} \mathrm{C}$ for $45 \mathrm{~s}$.

PCR products obtained using primers Spiro-1f and Spiro-2r from samples H1 and H5 were cloned into the plasmid vector pCR 2.1-TOPA using the TOPO TA Cloning kit (Invitrogen) according to the manufacturer's instructions. All samples were plated out on Luria-Bertani (LB) plates containing ampicillin $\left(50 \mu \mathrm{g} \mathrm{ml} \mathrm{m}^{-1}\right)$ and incubated at $37^{\circ} \mathrm{C}$ overnight. From each cloning reaction, 24 colonies were chosen and screened for the presence of transformants with inserts of the correct size using PCR and the primers M13 forward (5'-TGT AAA ACG ACG GCC AGT-3') and M13 reverse (5'-CAG GAA ACA GCT ATG ACC-3'). The M13 PCR reaction was incubated at $94^{\circ} \mathrm{C}$ for $10 \mathrm{~min}$ to lyse the cells and inactivate nucleases. The annealing temperature was set to $56^{\circ} \mathrm{C}$ for $45 \mathrm{~s}$, all other settings were as described above.

All PCR products were purified using the NucleoSpin Extract II (Macherey Nagel) according to the manufacturer's instructions, and sequenced on both strands using the PCR primers and the internal sequencing primers for the SSU rDNA fragments: Spiro-3f (5'-CAT TGG GYA ATY TYC GCG CCT-3'), Spiro-4r (5'-GAY TCY GGA GAV TGR GCA YGA G-3'), Spiro-5f (5'-STY TCC GTC AAT MCY TTM AAG TTT C-3') and Spiro-6r (5'-AAG RYT GAA ACT TKA ARG KAT TGA CGG-3'), as previously described (Jørgensen \& Sterud 2004). All products were sequenced using DyeET ${ }^{\mathrm{TM}}$ chemistry (GE Health) and analysed on a MegaBACE 1000 sequence analysis 
system (GE Health) according to the manufacturer's instructions. PCR products from positive clones were sequenced using primers Spiro-4r and Spiro-5f only.

\section{Sequence identification}

The raw sequence data were manually edited using the Vector NTI software package (Invitrogen) and included in a BLAST search at the National Centre for Biotechnology Information (NCBI) for identification. Spironucleus sequences were subsequently aligned against SSU rDNA sequences from S. salmonicida, S. barkhanus and $S$. salmonis retrieved from GenBank (accession numbers U93083, DQ186576, DQ394704, respectively). Alignments were manually read to check for misalignments before they were subjected to Neighbor-Joining (NJ) analyses using MEGA4 (see Fig. 2). The NJ analysis was conducted using the maximum composite likelihood substitution model, uniform rates among sites and complete deletion of positions with gaps and missing data. Bootstrap support analysis (1000 replicates) was used to estimate the confidence of the nodes within the resulting topologies.

\section{RESULTS}

A total of 320 fish (68 wild salmonids, 12 sticklebacks and 240 farmed smolts) were sampled and examined for the presence of diplomonad flagellates. All 17 wild fish samples positive by light microscopy (obtained in July) were subjected to molecular analyses. A total of 14 of these fish were PCR positive. In wild fish sampled in September (only subjected to molecular analyses), 2 of 33 fish were PCR positive for diplomonad flagellates (see Tables 1 \& 2 for more detailed information). All obtained SSU rDNA se- quences were subjected to NJ analysis together with known SSU rDNA sequences representing Spironucleus salmonicida, S. barkhanus and S. salmonis (GenBank accession numbers U93083, DQ186576, DQ394704, respectively). Three major assemblages representing the species $S$. salmonicida, S. barkhanus and $S$. salmonis were recovered (bootstrap support $>96 \%$ ) by the NJ analysis (Fig. 2a). The genetic variation between sequences within the assemblages was on average $0.5 \%$. Detailed information on parasite species identified, host records and target organs is provided in Fig. 2 and Table 2. In total, S. barkhanus was found in $30 \%$ of trout and $2.1 \%$ of Arctic char. $S$. salmonis was found in $4.2 \%$ of Arctic char and $33.3 \%$ of three-spined sticklebacks. S. salmonicida was found in $15 \%$ of trout and $8.3 \%$ of Arctic char.

Analyses of obtained SSU rDNA sequence data (GenBank accession numbers JF750347 to JF750365, Fig. 2, Table 2) showed that Spironucleus salmonicida was found in fish from all 3 lakes, while $S$. barkhanus and $S$. salmonis were found only in the Landersfjordvatnet and Helvetjavrri lakes (Table 2). S. salmonicida, S. barkhanus and S. salmonis were found in both wild brown trout and wild Arctic char. All 3 species were present in samples from the intestine, while only $S$. barkhanus was found in samples from bile (Table 2, Fig. 2). The 2 independent nested PCR reactions, employing Spironucleus general and S. salmonicida-specific primers (in second round reactions), generated sequence data from different Spironucleus species in single samples of intestinal content from 2 fish (HJ1 and HJ5). Furthermore, a dual infection was identified in sample LFV 10 (Table 2, Fig. 2a) where S. salmonicida and $S$. barkhanus were found in the intestine and gall bladder, respectively. The PCR products from samples HJ1 and HJ5, generated using general Spironucleus primers, were subjected to cloning. The obtained sequences have been deposited in GenBank under

Table 1. Fish sampled for Spironucleus spp. in 2008. Sample localities, number of samples, and number of positive samples by light microscopy (July only) and PCR (July and September)

\begin{tabular}{|c|c|c|c|c|c|c|}
\hline \multirow[t]{2}{*}{ Species } & \multirow[t]{2}{*}{ Sample locality } & \multirow[b]{2}{*}{ No. of fish } & \multicolumn{2}{|c|}{$\begin{array}{l}\text { July } \\
\text { - No. positive }\end{array}$} & \multicolumn{2}{|c|}{ September } \\
\hline & & & - No. posi & $\overline{\mathrm{PCR}}$ & No. of fish & No. positive \\
\hline Trout & Landersfjordvatnet & 19 & 11 & 10 & 0 & - \\
\hline Trout & Helvetjavrri & 1 & 1 & 1 & 0 & - \\
\hline Arctic char & Helvetjavrri & 7 & 4 & 3 & 5 & 1 \\
\hline Arctic char & Store Måsvatn & 8 & 1 & 1 & 28 & 1 \\
\hline Freshwater smolt & Farm & 80 & 0 & 0 & 40 & 0 \\
\hline Saltwater smolt & Farm & 80 & 0 & 0 & 40 & 0 \\
\hline Stickleback & Farm & 12 & 5 & 4 & 0 & - \\
\hline
\end{tabular}


Table 2. Spironucleus spp. infecting Salmo trutta, Salvelinus alpinus and Gasterosterus aculeatus. Spironucleus species identified, host species and target organs. NA: not analysed; HJ: Helvetjavrri; LFV: Landersfjordvatnet; SB: three-spined sticklebacks from the fish farm; SM: Store Måsvatn

\begin{tabular}{|c|c|c|c|}
\hline \multirow{2}{*}{$\begin{array}{l}\text { Sample } \\
\text { ID }\end{array}$} & \multirow[t]{2}{*}{ Host } & \multicolumn{2}{|c|}{ cies found/GenBank acc. no(s). } \\
\hline & & Intestine & Gall bladder \\
\hline LFV 1 & Brown trout & S. salmonicida/JF750354 & Negative \\
\hline LFV 2 & Brown trout & S. salmonicida/JF750358 & Negative \\
\hline LFV 5 & Brown trout & S. barkhanus/JF750360 & S. barkhanus/JF750359 \\
\hline LFV 8 & Brown trout & S. barkhanus/JF750362 & S. barkhanus/JF750361 \\
\hline LFV 10 & Brown trout & S. salmonicida/JF750355 & S. barkhanus ${ }^{\mathrm{a}}$ \\
\hline LFV 11 & Brown trout & S. barkhanus ${ }^{\mathrm{a}}$ & S. barkhanus/JF750356 \\
\hline LFV 16 & Brown trout & Negative & S. barkhanus/JF750357 \\
\hline HJ 1 & Arctic char & S. salmonicida and S. salmonis/JF750348/JF750349 & NA \\
\hline HJ 3 & Arctic char & S. salmonicida/JF750352 & NA \\
\hline HJ 5 & Arctic char & S. salmonicida and S. salmonis/JF750347/JF750353 & NA \\
\hline HJ 10 & Arctic char & S. barkhanus/JF750350 & NA \\
\hline HJ 13 & Brown trout & S. barkhanus/JF750351 & NA \\
\hline SM 3 & Arctic char & S. salmonicida/JF750365 & NA \\
\hline SB 3 & Three-spined stickleback & S. salmonis/JF750364 & NA \\
\hline SB 4 & Three-spined stickleback & S. salmonis ${ }^{\mathrm{a}}$ & NA \\
\hline SB 11 & Three-spined stickleback & S. salmonis/JF750363 & NA \\
\hline SB 12 & Three-spined stickleback & S. salmonis ${ }^{\mathrm{a}}$ & NA \\
\hline
\end{tabular}

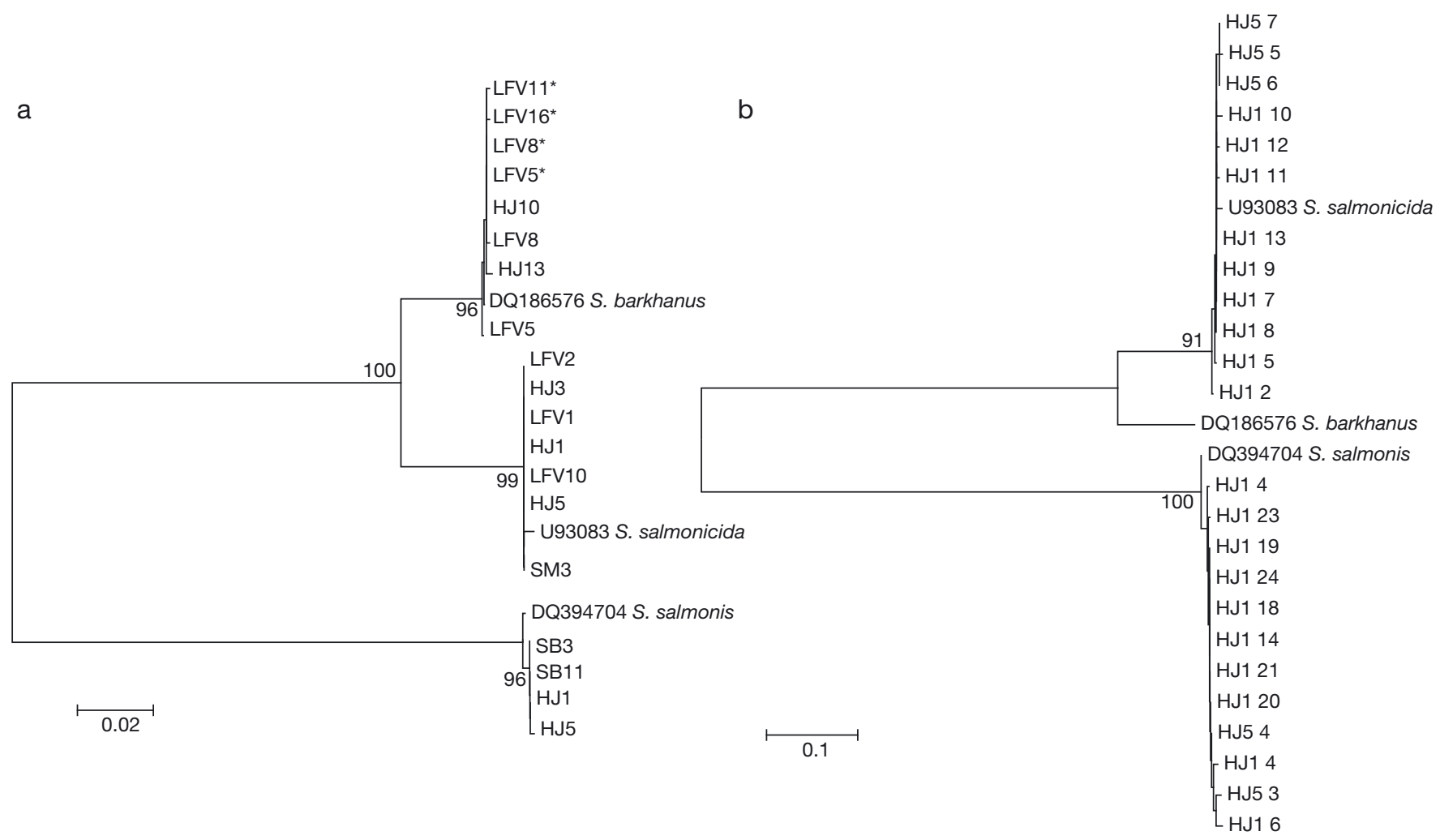

Fig. 2. Phylogenetic analyses of Spironucleus species isolated from fish sampled in the northern Norwegian lakes Helvetjavrri (HJ), Landersfjordvatnet (LFV) and Store Måsvatn (SM), and three-spined sticklebacks from the smolt farm (SB). (a) NeighborJoining (NJ) analysis based on 752 positions (positions with gaps deleted) of the small subunit ribosomal RNA gene (SSU rDNA) of directly sequenced PCR products. Sequences are deposited in GenBank under accession numbers JF750347 to JF750365. (b) NJ analysis based on 473 positions (positions with gaps deleted) of the SSU rDNA of cloned PCR products from samples HJ1 and HJ5. Sequences obtained from clones are deposited in GenBank under accession numbers JF750366 to JF750388. For both analyses, bootstrap support values above $70 \%$ are indicated at the nodes. All sequences are presented with sample IDs according to sample locality, clones are also listed with numbers. Sequences obtained from samples isolated from bile are indicated with an asterisk, all other sequences were obtained from samples of intestinal digesta/mucosa. Sequences retrieved from GenBank are indicated with species names and accession numbers. The scale bars represent number of nucleotide substitutions per site 
accession numbers JF750366 to JF750388. Six and 19 clones with an insert of correct size were obtained for HJ1 and HJ5, respectively. All PCR-positive clones were sequenced, and subjected to NJ analysis with sequences representing $S$. salmonicida, $S$. barkhanus and $S$. salmonis included (as described above). The cloned sequences clustered with $S$. salmonis and $S$. salmonicida with strong bootstrap support (Fig. 2b), demonstrating the presence of a coinfection of $S$. salmonicida and $S$. salmonis in these samples.

A total of 240 smolts from the farm (both sampling periods) were also examined; 120 fish were obtained from freshwater and 120 fish from saltwater. No diplomonad flagellates were detected by light microscopy or by PCR. Spironucleus salmonis was identified in samples of intestinal content from 4 of 12 three-spined sticklebacks taken from freshwater tanks at the farm.

\section{DISCUSSION}

\section{Infection source}

In December 2007, an Atlantic salmon farm situated in the Alta fjord experienced an outbreak of spironucleosis in fish supplied by Company A. Fish from another supplier (Company B) were also kept at the same location. The smolt from the 2 suppliers were transferred to sea at the same time of year and kept in adjacent net cages. At slaughter, 100 and 77 fish originating from Company A and Company B, respectively, were sampled. Spironucleosis was diagnosed in $25 \%$ of the fish from Company A, while no signs of spironucleosis were seen in fish from Company B (data not shown). The present study has demonstrated that Spironucleus salmonicida is present in both wild Arctic char and wild brown trout in the 3 lakes used as water sources for Company A. S. salmonicida was not found in any of the fish sampled at the smolt farm (Company A). However, based on all available information, it is likely that fish that developed spironucleosis were infected before being transferred to the sea. A possible explanation may be that smolt were not infected by the parasite in this particular season; this is supported by the fact that there were no reports of systemic spironucleosis in these fish after they were transferred to the sea. Furthermore, not all stocks of Atlantic salmon smolt supplied by Company A have developed spironucleosis, indicating that the problem is sporadic, making the parasite hard to detect in smolts from the farm.
Spironucleus salmonicida was found in all 3 lakes (Fig. 1) used as water sources for Company A. The largest of these 3 lakes (Store Måsvatn) is connected by streams and rivers to several other lakes on the mountain plateau Finnmarksvidda. It is thus probable that the parasite is present in other lakes on Finnmarksvidda. Several smolt-producing companies use lakes on Finnmarksvidda as their water source, thus Company A is probably not the only smolt producer exposed to $S$. salmonicida. The diagnosis of spironucleosis in farmed Arctic char in Vesterålen (Norway) (Jørgensen \& Sterud 2004) and in farmed chinook salmon in Canada (Kent et al. 1992) also substantiate the notion of a wide geographic distribution of $S$. salmonicida. Moreover, spironucleosis has also been reported from wild chinook salmon in Lake Ontario (Meseck et al. 2007). This parasite was not identified to species level; however, a systemic infection was caused by a diplomonad flagellate probably belonging to the genus Spironucleus (Meseck et al. 2007). Most of the fish studied were sampled during the spawning season, suggesting that the problem is connected to the presumed immunocompromised state of salmonids during spawning. Thus, the fact that only farmed Atlantic salmon from a few suppliers develop spironucleosis can possibly be explained by their reduced general health status combined with exposure to the parasite.

\section{Dual Spironucleus infections in wild salmonids}

Dual infections were detected in 3 fish by both cloning and nested PCR with 2 sets of second round primers (see 'Materials and methods'). Samples HJ1 and HJ5 were selected for cloning based on ambiguities in the sequence obtained initially. In individual PCR reactions, the general primers (Spiro-1 and Spiro-2) amplified Spironucleus salmonicida and $S$. salmonis both together and independently, as detected by sequence analysis. The $S$. salmonicidaspecific primers generated $S$. salmonicida sequence data only from the same samples. Samples HJ1 and HJ5 probably contained equal amounts of target DNA from $S$. salmonicida and S. salmonis. By chance, 1 of the 2 species may sometimes be overrepresented in individual PCR reactions, while on other occasions, amplicons from both species would be produced in equal amounts, causing ambiguities in the generated sequence data. The number of dual infections in our material may be significantly higher than detected, as only 2 samples (HJ1 and HJ5) were cloned. In addition, infections with all 3 Spironucleus species in 
individual fish may also be present in our material even though they were not detected.

In some samples, only short sequences could be obtained. Intestinal samples from fish may be a challenge for downstream molecular applications due to inhibitors (Wilson 1997). This is supported by the fact that some samples identified as positive by light microscopy did not amplify by PCR (Table 1). However, this could also be due to the presence of novel diplomonad species with SSU rDNA sequences that do not match the primers used.

\section{Implications}

The present study is the first report of wild salmonid hosts and potential reservoirs of Spironucleus salmonicida in the intestine of wild brown trout and wild Arctic char. Jørgensen \& Sterud (2004, 2006) have previously studied diplomonad flagellates in wild Arctic char using molecular methods. However, only flagellates isolated from bile were included and thus only $S$. barkhanus was identified. The present study indicates that $S$. barkhanus is the only diplomonad that can be found in the gall bladder (as well as in the intestine) of salmonid fish in Norway, while $S$. salmonicida and $S$. salmonis are restricted to the intestine. Thus, S. salmonicida and S. salmonis may have been present in the fish studied by Jørgensen \& Sterud $(2004,2006)$, but were missed due to the lack of intestinal samples. Furthermore, all previous reports and descriptions of intestinal diplomonad flagellates in salmonid fish could comprise at least 3 different species: $S$. barkhanus, $S$. salmonicida and S. salmonis, or a mixture of these species. Infections with multiple species/genotypes in individual hosts have also been demonstrated for Giardia, a close relative of Spironucleus (Read et al. 2004, Sprong et al. 2009, Cacciò \& Sprong 2010). Together, these highlight the need for the use of molecular techniques, including cloning, when studying diplomonad flagellates from fish or other animals.

Acknowledgements. This work was supported by the Norwegian Veterinary Institute, the Norwegian School of Veterinary Science and Grieg Seafood Finnmark AS.

\section{LITERATURE CITED}

Cacciò SM, Sprong H (2010) Giardia duodenalis: Genetic recombination and its implications for taxonomy and

Editorial responsibility: Dieter Steinhagen,

Hannover, Germany molecular epidemiology. Exp Parasitol 124:107-112

> Fiala I (2006) The phylogeny of Myxosporea (Myxozoa) based on small subunit ribosomal RNA gene analysis. Int J Parasitol 36:1521-1534

> Jørgensen A, Sterud E (2004) SSU rRNA gene sequence reveals two genotypes of Spironucleus barkhanus (Diplomonadida) from farmed and wild Arctic charr Salvelinus alpinus. Dis Aquat Org 62:93-96

Jørgensen A, Sterud E (2006) The marine pathogenic genotype of Spironucleus barkhanus from farmed salmonids redescribed as Spironucleus salmonicida n. sp. J Eukaryot Microbiol 53:531-541

- Kent ML, Ellis J, Fournie JW, Dawe SC, Bagshaw JW, Whitaker DJ (1992) Systemic hexamitid (Protozoa: Diplomonadida) infection in seawater pen-reared chinook salmon Oncorhynchus tshawytscha. Dis Aquat Org 14: 81-89

> Medlin L, Elwood HJ, Stickel S, Sogin ML (1988) The characterization of enzymatically amplified eukaryotic 16Slike rRNA-coding regions. Gene 71:491-499

Meseck EK, French TW, Grimmett SG, Bartlett SL and others (2007) Gross and microscopic pathology associated with large cavernous lesions in muscle of chinook salmon from Lake Ontario. J Wildl Dis 43:111-115

Mo TA, Poppe TT, Iversen L (1990) Systemic hexamitosis in salt-water reared Atlantic salmon (Salmo salar L.). Bull Eur Assoc Fish Pathol 10:69-70

Paull GC, Matthews RA (2001) Spironucleus vortens, a possible cause of hole-in-the-head disease in cichlids. Dis Aquat Org 45:197-202

Poppe TT, Mo TA (1993) Systemic, granulomatous hexamitosis of farmed Atlantic salmon: interaction with wild fish. Fish Res 17:147-152

Poppe TT, Mo TA, Iversen L (1992) Disseminated hexamitosis in sea-caged Atlantic salmon Salmo salar. Dis Aquat Org 14:91-97

Poynton SL, Sterud E (2002) Guidelines for species descriptions of diplomonad flagellates from fish. J Fish Dis 25: 15-31

> Read CM, Monis PT, Thompson RC (2004) Discrimination of all genotypes of Giardia duodenalis at the glutamate dehydrogenase locus using PCR-RFLP. Infect Genet Evol $4: 125-130$

Sprong H, Cacciò SM, van der Giessen JWB, on behalf of the ZOOPNET network and partners (2009) Identification of zoonotic genotypes of Giardia duodenalis. PLoS Negl Trop Dis 3: e558

Sterud E, Mo TA, Poppe TT (1997) Ultrastructure of Spironucleus barkhanus n. sp. (Diplomonadida: Hexamitidae) from grayling Thymallus thymallus (L.) (Salmonidae) and Atlantic salmon Salmo salar L. (Salmonidae). J Eukaryot Microbiol 44:399-407

> Sterud E, Mo TA, Poppe TT (1998) Systemic spironucleosis in sea-farmed Atlantic salmon Salmo salar, caused by Spironucleus barkhanus transmitted from feral Arctic char Salvelinus alpinus? Dis Aquat Org 33:63-66

Sterud E, Poppe T, Bornø G (2003) Intracellular infection with Spironucleus barkhanus (Diplomonadida: Hexamitidae) in farmed Arctic char Salvelinus alpinus. Dis Aquat Org 56:155-161

- Wilson IG (1997) Inhibition and facilitation of nucleic acid amplification. Appl Environ Microbiol 63:3741-3751

Submitted: April 6, 2011; Accepted: August 16, 2011

Proofs received from author(s): October 25, 2011 